\title{
РАЗРАБОТКА СЕТЕВОЙ МОДЕЛИ УПРАВЛЕНИЯ КАЧЕСТВОМ БЫТОВЫХ УСЛУГ
}

\author{
(C) 2020 Домнин Антон Дмитриевич \\ аспирант, Высшая инженерно-экономическая школа \\ Санкт-Петербургский политехнический университет Петра Великого (СПбПУ), \\ Россия, Санкт-Петербург \\ E-mail:domnin_a@mail.ru \\ (c) 2020 Барыкин Сергей Евгеньевич \\ доктор экономических наук, профессор, Высшая школа сервиса и торговли \\ Санкт-Петербургский политехнический университет Петра Великого (СПбПУ), \\ Россия, Санкт-Петербург \\ E-mail: sbe@list.ru
}

Формы и направления предпринимательской активности хозяйствующих субъектов в сегментах бытовых услуг отличаются значительным разнообразием. Это обусловлено разнородностью объектов предложения и спроса на бытовые услуги, сложностью половозрастной и социальной структуры потребителей, избирательностью реакций на методы продвижения и стимулирования спроса. Для бытовых услуг характерны существенные различия в ресурсоемкости, часть бытовых услуг обладает свойствами осязаемости и хранимости. Вследствие указанных различий возникают различия в детерминантах качества бытовых услуг: для некоторых из них более значимо качество сырья, материалов, оборудования, для других - ключевым параметром являются квалификационные и личностные качества работников, менеджеров и руководителей предприятий бытового обслуживания населения (БОН). Указанные различия являются причиной множественности и неоднозначности классификаций видов БОН и определений их качества. В статье разработана сетевая модель управления качеством бытовых услуг.

Ключевые слова: бытовое обслуживание населения, бытовые услуги, сетевая модель, менеджмнт качества

\section{Введение}

Проблемы управления качеством услуг широко освещены в трудах таких отечественных и зарубежных исследователей, но библиографический поиск показал, что количество исследований, посвященных развитию предложения бытовых услуг, повышения их качества и доступности для широких слоев городского и сельского населения и опубликованных после 1990-х годов существенно сократилось по сравнению с периодом 1970-х - 1980-х годов. В частности, недостаточно разработаны возможности использования добровольных объединений и ассоциацией предпринимателей, оказывающих бытовые услуги, для повышения эффективности контроля качества. Кроме того, в существенно меньшей степени, чем для промышленного производства, разработано инструментальное обеспечения контроля качества бытовых услуг.

В основе любого классификационного признака должно лежать четкое и обоснованное представление об экономической сущности классифицируемых объектов. Это предполагает выяснение роли и назначения бытовых услуг населению в структуре спроса и предложения на рынке услуг [18, 29].

В экономической науке существует весьма разработанная теория функционирования сферы услуг, в основе которой лежат труды А. Смита, Д.Рикардо, К. Маркса. Последующее уточнение категория «услуга» получила в теории непроизводственной сферы, в которой дискутировали две точки зрения по сущности услуги: как полезного результата труда, предназначенного для личного потребления; как специфического отношения, непроизводственного обмена труда на доход.

В зарубежных работах по маркетингу [1-14, 21] рассматривается связка товар-услуга и всевозможные их комбинации с преобладанием свойств товара или услуги. Исходя из этого, услуга представляется результатом взаимодействия 
объектов и субъектов, а не самой деятельностью. Обобщая вышеприведенные точки зрения на экономическую природу услуг, Л. М.Кликич к наиболее распространенным ошибкам в трактовке сущности услуг относит: сведение ее к определенному функциональному содержанию конкретного труда или к его характеристикам, а также отождествление услуги с непроизводственной деятельностью или с товаром. Данный автор считает, что рассматриваемая в политэкономическом плане категория «услуга», выражает не полезное действие труда и не его результат, а специфическое экономическое отношение, отношение по поводу общественного труда. Услуговая форма обмена общественного труда противостоит товарной. Основное отличие между ними состоит в том, что товар - это материализованный и отчужденный от производителя результат труда $[15,22]$. Он доводится до обезличенного потребителя через рынок с использованием стандартных процедур через сеть посредников - перекупщиков. Между потреблением и производством товара всегда есть временной лаг. Услуга же одновременно является и объектом, и носителем специфического экономического субъект-субъектного отношения по поводу общественного обмена труда по заказу [23, 30].
Процесс ее потребления, как правило, совпадает с процессом производства, поскольку в основе её оказания единый процесс производства и персонального потребления. Услуговую форму обмена отличает от товарной прямая связь производителя и потребителя, её результатом не является осязаемый, материализованный продукт труда [16, 24].

\section{Взаимодействие предпринимателей и администрациями муниципальных образо-} ваний

Сфера услуг, являющаяся составной частью малого бизнеса, сталкивается с проблемами, характерными для большинства предпринимателей, отмеченными многими исследователями $[19,22,25,26,31,32]:$

- отсутствие производственных площадей соответствующих санитарным нормам и правилам для размещения предприятий бытового обслуживания;

- трудности в получении кредитных ресурсов и привлечении инвестиций;

- нехватка квалифицированных кадров, особенно рабочих профессий (портные, закройщики, сапожники, специалисты по ремонту сложной техники);

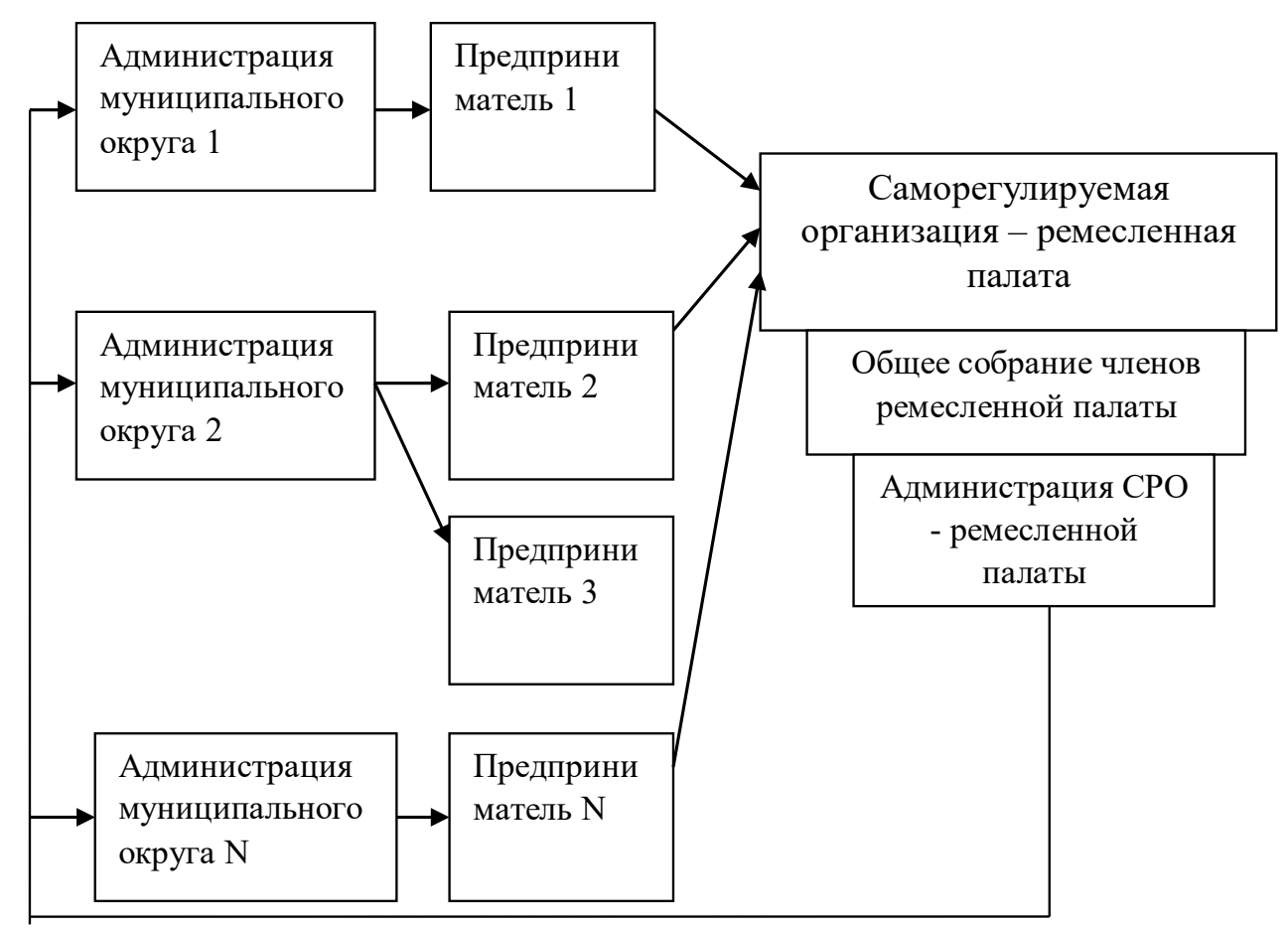

Рисунок 1. Схема взаимодействий в саморегулируемой организации ремесленной палате [составлено авторами] 


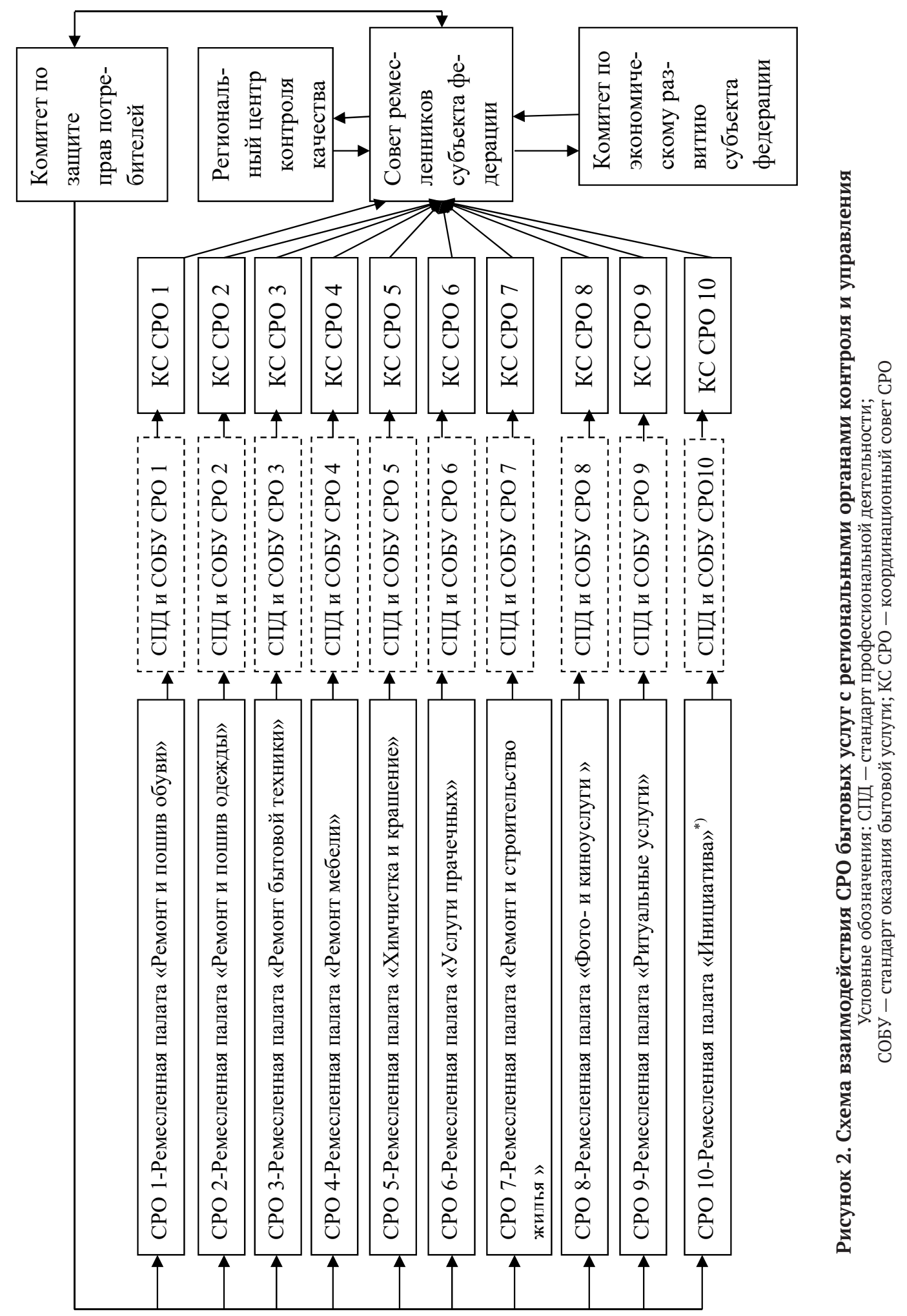


- несовершенство правового регулирования отрасли на федеральном и региональном уровнях;

- необходимость повышения уровня обслуживания и качества предоставляемых услуг;

- ценовые барьеры в получении бытовых услуг гражданами со средним и низким достатком;

- недостаточная информированность населения о предприятиях бытового обслуживания и оказываемых ими услугах.

Проблемы качества бытовых услуг, отмеченные экспертами, могут быть решены на основе объединения предпринимателей в саморегулируемые организации - ремесленные палаты по каждому профилю бытовых услуг [28]. Примерная схема структуры саморегулируемой организации - ремесленной палаты приведена на рисунке 1.

Данная схема предполагает создание корпоративных (цеховых) стандартов и позволяет усовершенствовать взаимодействие предпринимателей и администрациями муниципальных образований, на территории которых они оказывают бытовые услуги, а также усилить контроль за их деятельностью. На рисунке 2 представлена схема взаимодействия саморегулируемых организаций - ремесленных палат с администрацией субъекта федерации.

Членство в саморегулируемой организации предприятий БОН (СРО БОН), в соответствии с приведенными выше положениями, в качестве фундаментального правила должно предполагать проведение единой политики в области качества, что предполагает принятие программного документа общим собранием членов СРО БОН.

\section{Система принципов для разработки мо- дели}

Построение модели менеджмента качества базируется на следующей системе принципов [18].

Принцип ориентации на потребителя предполагает изучение потребностей (запросов) потребителей, их интересов и покупательной способности. Данный принцип предполагает разработку стратегии качества услуг, основанной на опережающем знании интересов потребителей.

Принцип лидерства руководителя означает, что стратегия качества формируется при опре- деляющей роли руководителя в принятии основополагающих решений.

Принцип вовлечения работников требует участия каждого из сотрудников фирмы в создании качественной услуги на всех этапах его жизненного цикла.

Принцип процессного подхода устанавливает, что желаемый результат более эффективен, когда деятельностью по созданию услуги и соответствующими ресурсами управляют как процессом.

Принцип системного подхода к менеджменту означает, что результативность и эффективность оказания услуг достигается за счет подхода к менеджменту как к менеджменту взаимосвязанных процессов.

Принцип постоянного улучшения требует рассматривать непрерывное совершенствование деятельности фирмы как неизменную ее цель.

Принцип принятия решений, основанных на фактах, задает ориентацию на поиск эффективного решения на основе привлечения фактов, статистики, использования обоснованных методов анализа.

Принцип взаимовыгодных отношений с поставщиками гласит, что фирма и ее поставщики взаимозависимы, и отношения взаимной выгоды повышают способность обеих сторон создавать ценности.

\section{Формирование сетевой модели}

В соответствии с представленной на рисунке 2 схемой взаимодействий между региональными, муниципальными органами власти и предпринимателями можно определить следующее содержание работ при создании бытового мультисервиса как организационной формы объединения предпринимателей для обеспечения качественных бытовых услуг:

1-2 - разработка положения о бытовом мультисервисе;

3-4 - определение состава членов бытового мультисервиса;

4-13 - создание координационного совета членов бытового мультисервиса;

5-6 - создание системы менеджмента качества каждым членом бытового мультисервиса;

8-6 - создание комиссии по контролю качества услуг бытового мультисервиса;

6-7 - разработка регламента контроля качества услуг бытового мультисервиса; 
9-10 - разработка регламента оказания услуг социально незащищенным группам населения;

11-12 - разработка мер дисциплинарного воздействия на нарушителей регламента контроля качества;

12-13 - прекращение деятельности предприятий бытового обслуживания, оказывающих некачественные услуги, в соответствии с положением о бытовом мультисервисе;

14-15 - разработка правил производственной безопасности оказания бытовых услуг членами бытового мультисервиса;

16-17 - разработка правил санитарногигиенической безопасности оказания бытовых услуг;

18-19- разработка условий предоставлений скидок постоянным клиентам;

19-28 - оказание бытовых услуг членами мультисервиса постоянным клиентам;

20-21 - проведение анкетирования потребителей;

22-23 - разработка мероприятий по предупреждению жалоб потребителей членами бытового мультисервиса;

24-25 - разработка мероприятий по предотвращению жалоб на бытовые услуги;

26-27 - разработка программы бытового мультисервиса как центра высокого качества услуг;

27-28 - оказание бытовых услуг новым потребителям.

Сетевая модель представлена на рисунке 3 . Оптимистические и пессимистические оценки времени были определены экспертно, в качестве экспертов выступили директор строящегося торгово-развлекательного комплекса и директор бытового предприятия химчисткипрачечной. Ожидаемая оценка была определена по следующей формуле:

$$
t_{i j}=\frac{2 t_{\max }+3 t_{\min }}{5}
$$

где $t_{i j}$ - ожидаемая оценка;

$t_{\max }$ - оптимистическая оценка времени;

$t_{\min }$ - пессимистическая оценка времени

Расчеты критического пути проводились на основе предположения, что продолжительность работ по созданию системы менеджмента качества не превысит 5 месяцев. Для конкретизации был принят период с 01.08.17 по 31.12.17, т.е. 153 дня.

Экспертные и расчетная ожидаемая оценки продолжительности работ представлены в таблицах 1-3.

\section{Таблица 1. Продолжительность маркетинговых работ}

\begin{tabular}{|c|c|c|c|}
\hline Коды работ & $\begin{array}{c}\text { Оптимистическая оценка, } \\
\text { дней }\end{array}$ & $\begin{array}{c}\text { Пессимистическая оценка, } \\
\text { дней }\end{array}$ & $\begin{array}{c}\text { Ожидаемая оценка, } \\
\text { дней }\end{array}$ \\
\hline $1-2$ & 1 & 3 & 2 \\
\hline $3-4$ & 1 & 3 & 22 \\
\hline $4-13$ & 7 & 30 & 12 \\
\hline $5-6$ & 10 & 15 & 30 \\
\hline $8-6$ & 7 & 40 & 5 \\
\hline $6-7$ & 15 & 5 & 21 \\
\hline $9-10$ & 3 & 3 & 2 \\
\hline $11-12$ & 1 & 30 & 2 \\
\hline $12-13$ & 7 & 3 & 2 \\
\hline $14-15$ & 1 & 3 & 21 \\
\hline $16-17$ & 1 & 3 & 21 \\
\hline $18-19$ & 1 & 30 & 2 \\
\hline $19-28$ & 7 & 30 & 2 \\
\hline $20-21$ & 7 & 15 & 5 \\
\hline $22-23$ & 7 & 5 & 3 \\
\hline $24-25$ & 3 & 30 & 2 \\
\hline $26-27$ & 1 & & \\
\hline $27-28$ & 7 & 3 & \\
\hline
\end{tabular}




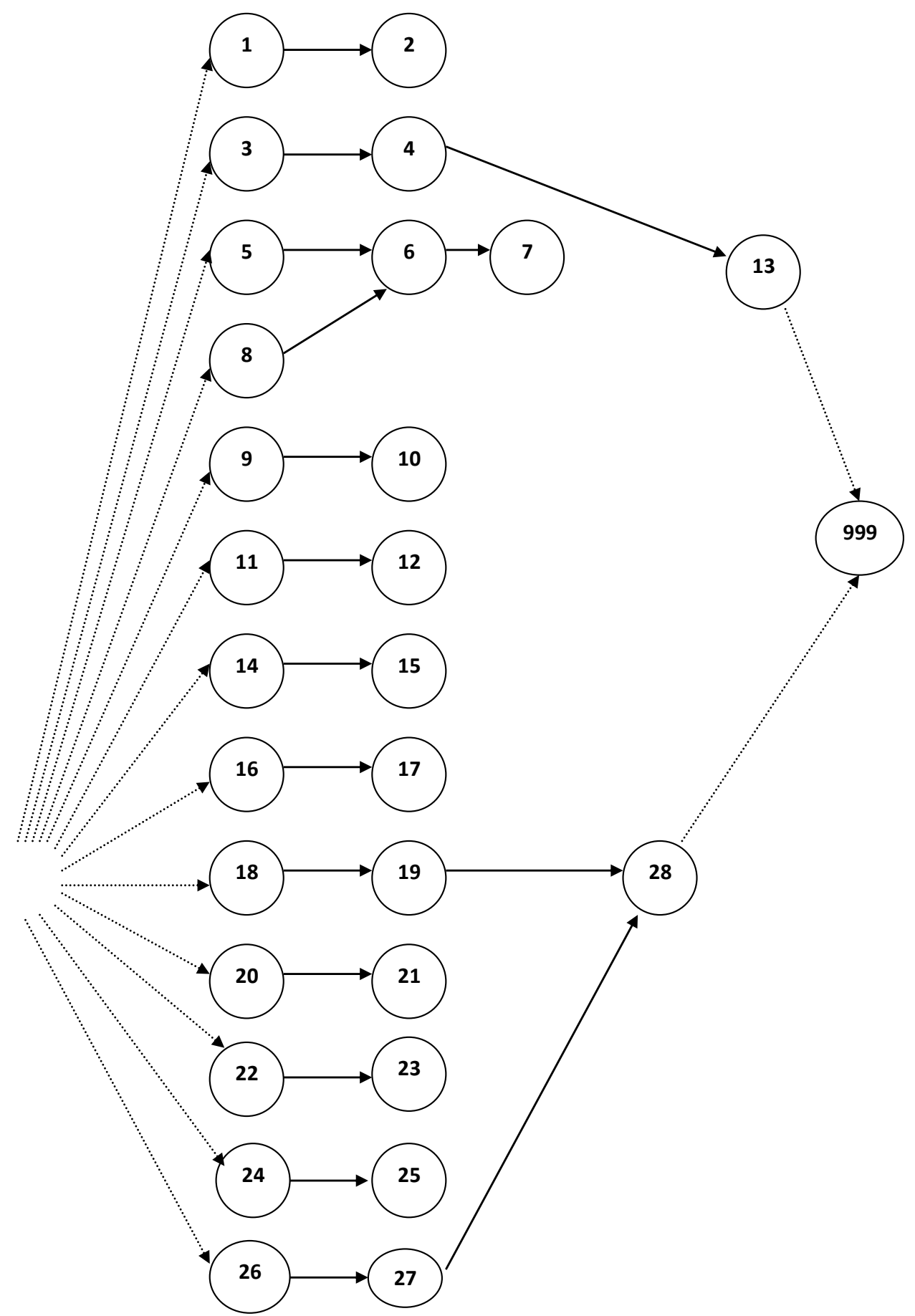

Рисунок 3. Сетевая модель создания системы менеджмента качества в мультисервисе 
Параметры сетевой модели рассчитывались в соответствии со стандартным алгоритмом.

Ранний возможный срок наступлений событий $\mathrm{T}_{\mathrm{j}} \mathrm{p}$ - минимальный из возможных моментов наступления данного события при заданных продолжительностях работ и начальном моменте без учета директивного срока завершения комплекса работ:
0 , если $\mathrm{j}=\mathrm{j}_{0}-$ исходное событие

$\mathrm{T}_{\mathrm{j}} \mathrm{p}=\max \left(\mathrm{T}_{\mathrm{j}} \mathrm{p}+\mathrm{t}_{\mathrm{ij}}\right), \mathrm{j} \neq \mathrm{j}_{0}$,

$\mathrm{i} \subseteq \mathrm{B}(\mathrm{b})_{\mathrm{j}}$

где $\mathrm{B}(\mathrm{b})_{j}-$ множество событий $\mathrm{i}$, соединенных с событием ј работами (ij), входящими в j-e событие.

Результаты расчетов представлены в табл. 2 .

Таблица 2. Расчет раннего срока наступления событий

\begin{tabular}{|c|c|c|c|}
\hline \multicolumn{2}{|c|}{ Коды входящих работ } & \multirow{2}{*}{$\begin{array}{c}\text { Продолжительность } \\
\text { работы } t_{i j} \text {, дней }\end{array}$} & \multirow{2}{*}{$\begin{array}{c}\text { Ранний срок } \\
\text { наступления, } \mathrm{T}_{\mathrm{j}} \mathrm{p}\end{array}$} \\
\hline Событие i & Событие j & & \\
\hline 777 & 1 & 0 & 0 \\
\hline 1 & 2 & 2 & 2 \\
\hline 777 & 3 & 0 & 0 \\
\hline 3 & 4 & 2 & 2 \\
\hline 777 & 5 & 0 & 0 \\
\hline $\begin{array}{l}5 \\
8\end{array}$ & $\begin{array}{l}6 \\
6\end{array}$ & $\begin{array}{l}22 \\
12\end{array}$ & 22 \\
\hline 6 & 7 & 30 & 52 \\
\hline 777 & 8 & 0 & 0 \\
\hline 777 & 9 & 0 & 0 \\
\hline $\begin{array}{l}9 \\
7\end{array}$ & $\begin{array}{l}10 \\
10\end{array}$ & $\begin{array}{l}5 \\
0\end{array}$ & 52 \\
\hline 777 & 11 & 0 & 0 \\
\hline $\begin{array}{l}11 \\
10\end{array}$ & $\begin{array}{l}12 \\
12\end{array}$ & $\begin{array}{l}5 \\
0\end{array}$ & 52 \\
\hline 777 & 14 & 0 & 0 \\
\hline $\begin{array}{l}16 \\
15\end{array}$ & $\begin{array}{l}17 \\
17\end{array}$ & $\begin{array}{l}2 \\
0\end{array}$ & 2 \\
\hline 777 & 18 & 0 & 0 \\
\hline 20 & 21 & 21 & 21 \\
\hline 777 & 22 & 0 & 0 \\
\hline 22 & 23 & 12 & 12 \\
\hline 777 & 24 & 0 & 0 \\
\hline $\begin{array}{l}24 \\
21 \\
23\end{array}$ & $\begin{array}{l}25 \\
25 \\
25\end{array}$ & $\begin{array}{l}5 \\
0 \\
0\end{array}$ & 12 \\
\hline 777 & 26 & 0 & 0 \\
\hline 26 & 27 & 2 & 2 \\
\hline $\begin{array}{c}4 \\
12\end{array}$ & $\begin{array}{l}13 \\
13\end{array}$ & $\begin{array}{l}21 \\
21\end{array}$ & 73 \\
\hline $\begin{array}{l}19 \\
27\end{array}$ & $\begin{array}{l}28 \\
28\end{array}$ & $\begin{array}{l}21 \\
21\end{array}$ & 23 \\
\hline $\begin{array}{l}13 \\
28\end{array}$ & $\begin{array}{l}999 \\
999\end{array}$ & $\begin{array}{l}0 \\
0\end{array}$ & 73 \\
\hline
\end{tabular}


Поздний допустимый срок наступления $\mathrm{T}_{\mathrm{j}}-$ максимальный из допустимых моментов наступления данного события, при котором еще возможно выполнение всех последующих работ с соблюдением раннего срока наступления завершающего события (или с соблюдением директивного срока, ели он задан).
$\mathrm{T}_{\mathrm{iw}} \mathrm{p}$, если $\mathrm{j}=\mathrm{j}_{\mathrm{w}}-$ завершающее событие $\mathrm{T}_{\mathrm{i}^{\mathrm{I}}}=\min \left(\mathrm{T}_{\mathrm{r}} \mathrm{n}^{\mathrm{w}}-\mathrm{t}_{\mathrm{jr}}\right), \mathrm{j} \neq \mathrm{j}_{\mathrm{W}}$,

$\mathrm{r} \subseteq \mathrm{C}(\mathrm{u})_{j}$

где $\mathrm{C}(\mathrm{u})_{j}-$ множество событий $\mathrm{r}$, соединенных с ј-м событием работами (jr), выходящими из ј-го события.

\section{Таблица 3. Расчет позднего срока наступления событий}

\begin{tabular}{|c|c|c|c|}
\hline \multicolumn{2}{|c|}{ Коды выходящих работ } & \multirow{2}{*}{$\begin{array}{c}\text { Продолжительность } \\
\text { Tij, дней }^{2}\end{array}$} & \multirow{2}{*}{$\begin{array}{r}\text { Поздний срок } \\
\text { наступления } \mathrm{T}_{\mathrm{j}}{ }^{\mathrm{I}}\end{array}$} \\
\hline Событие j & Событие r & & \\
\hline 999 & & & 73 \\
\hline 28 & 999 & 0 & 73 \\
\hline 27 & 28 & 21 & 52 \\
\hline 26 & 27 & 2 & 50 \\
\hline 25 & 27 & 0 & 52 \\
\hline 24 & 25 & 5 & 47 \\
\hline 23 & 25 & 0 & 52 \\
\hline 22 & 23 & 12 & 40 \\
\hline 21 & 25 & 0 & 52 \\
\hline 20 & 21 & 21 & 31 \\
\hline 19 & 28 & 21 & 52 \\
\hline 18 & 19 & 2 & 50 \\
\hline 17 & 19 & 0 & 52 \\
\hline 16 & 17 & 2 & 50 \\
\hline 15 & 17 & 0 & 52 \\
\hline 14 & 15 & 2 & 48 \\
\hline 13 & 999 & 0 & 73 \\
\hline 12 & 13 & 21 & 52 \\
\hline 11 & 12 & 5 & 47 \\
\hline 10 & 12 & 0 & 52 \\
\hline 9 & 10 & 5 & 47 \\
\hline 8 & 6 & 12 & 10 \\
\hline 7 & 10 & 0 & 52 \\
\hline 6 & 7 & 30 & 22 \\
\hline 5 & 6 & 22 & 0 \\
\hline 4 & 13 & 21 & 52 \\
\hline 3 & 4 & 2 & 50 \\
\hline 2 & 4 & 0 & 50 \\
\hline 1 & 2 & 2 & 48 \\
\hline 777 & $\begin{array}{c}1 \\
3 \\
5 \\
8 \\
9 \\
11 \\
14 \\
16 \\
18 \\
20 \\
22 \\
24 \\
26\end{array}$ & $\begin{array}{l}0 \\
0 \\
0 \\
0 \\
0 \\
0 \\
0 \\
0 \\
0 \\
0 \\
0 \\
0 \\
0\end{array}$ & 0 \\
\hline
\end{tabular}


В соответствии с выполненными расчетами критическое время, равное раннему сроку наступления завершающего события, составляет 73 дня, так как Ткр. $=\mathrm{Tp}_{999}$.

В таблице 4, где представлены результаты расчетов параметров работ, использованы следующие обозначения и формулы расчета:

$\mathrm{t}_{\mathrm{ij}}$ - ожидаемая оценка продолжительностей работ;

$\mathrm{t}_{\mathrm{ij}}$ (р.н.) - ранний срок начала работ;

$\mathrm{t}_{\mathrm{ij}}$ (р.н.) $=\mathrm{Tp}_{\mathrm{i}}$

$\mathrm{t}_{\mathrm{ij}}$ (р.о.) - ранний срок окончания работы;

$\mathrm{t}_{\mathrm{ij}}$ (p.o.) $=\mathrm{Tp}_{\mathrm{i}}+\mathrm{t}_{\mathrm{ij}}$

$\mathrm{t}_{\mathrm{ij}}$ п.о.- поздний срок окончания работ;

$\mathrm{t}_{\mathrm{ij}}$ П.о. $=\mathrm{T}_{\mathrm{j}}$

$\mathrm{t}_{\mathrm{ij}}$ П.н.- поздний срок начала работ;

$\mathrm{t}_{\mathrm{ij}}$ П.н. $=\mathrm{T}_{\mathrm{j}}-\mathrm{t}_{\mathrm{ij}}$

$\mathrm{r}_{\mathrm{ij}}$ (п) - полный резерв времени работы;

$\mathrm{r}_{\mathrm{ij}}(\Pi)=\mathrm{T}_{\mathrm{j}}-\mathrm{Tp}_{\mathrm{i}}-\mathrm{t}_{\mathrm{ij}}$

$\mathrm{r}_{\mathrm{ij}}(\mathrm{c})$ - свободный резерв времени работы;

$\mathrm{r}_{\mathrm{ij}}(\mathrm{c})=\mathrm{Tp}_{\mathrm{j}}-\mathrm{Tp}_{\mathrm{i}}-\mathrm{t}_{\mathrm{ij}}$

Оптимизация сетевой модели в данном случае не требуется, так как критическое время составляет 73 дня, в то время как директивное время, за которое должен быть полностью выполнен весь комплекс маркетинговых работ, составляет 153 дня.

На рис. 4 представлен комплекс маркетин- говых работ и параметры сетевой модели. Для определения критического пути выберем работы, для которых $\mathrm{r}_{\mathrm{ij}}\left(\right.$ п) $=0, \mathrm{r}_{\mathrm{ij}}(\mathrm{c})=0$.

Как следует из результатов расчетов, критический путь образует следующая совокупность работ:

5-6 - создание системы менеджмента качества каждым членом бытового мультисервиса;

6-7 - разработка регламента контроля качества;

12-13 - прекращение деятельности предприятий бытового обслуживания, оказывающих некачественные услуги, в соответствии с положением о бытовом мультисервисе.

Следовательно, данные организационные аспекты деятельности бытового мультисервиса должны быть учтены в договоре аренды, заключаемом между собственником ТРК и предпринимателями, оказывающими бытовые услуги. В раздел договора «Обязанности арендатора» целесообразно включить следующие условия:

1. Арендатор обязуется разработать систему менеджмента качества бытовых услуг.

2. Арендатор обязывается вступить в члены координационного совета бытового мультисервиса и выполнять все требования регламента контроля качества бытового мультисервиса.

В раздел «Особые условия» целесообразно

Таблица 4. Параметры работ

\begin{tabular}{|c|c|c|c|c|c|c|c|}
\hline Коды работ & $t_{i j}$ & $\mathrm{t}_{\mathrm{ij}}$ (р.н.) & $t_{i j}$ (p.o.) & $\mathrm{t}_{\mathrm{ij}}$ П.н. & $\mathrm{t}_{\mathrm{ij}}$ П.о. & $\mathrm{r}_{\mathrm{ij}}{ }^{(\Pi)}$ & $\mathrm{r}_{\mathrm{ij}}(\mathrm{c})$ \\
\hline 1 & 2 & 3 & 4 & 5 & 6 & 7 & 8 \\
\hline $1-2$ & 2 & 0 & 2 & 48 & 50 & 48 & 0 \\
\hline $3-4$ & 2 & 0 & 2 & 50 & 52 & 50 & 0 \\
\hline $4-13$ & 21 & 2 & 23 & 52 & 73 & 50 & 30 \\
\hline $5-6$ & 22 & 0 & 22 & 0 & 22 & 0 & 0 \\
\hline $8-6$ & 12 & 0 & 12 & 10 & 22 & 10 & 10 \\
\hline $6-7$ & 30 & 22 & 52 & 22 & 52 & 0 & 0 \\
\hline $9-10$ & 5 & 0 & 5 & 47 & 52 & 47 & 47 \\
\hline $11-12$ & 5 & 0 & 5 & 47 & 52 & 47 & 47 \\
\hline $12-13$ & 21 & 52 & 73 & 52 & 73 & 0 & 0 \\
\hline $14-15$ & 2 & 0 & 2 & 50 & 52 & 50 & 0 \\
\hline $16-17$ & 2 & 0 & 2 & 50 & 52 & 50 & 0 \\
\hline $18-19$ & 2 & 0 & 2 & 50 & 52 & 50 & 0 \\
\hline $19-28$ & 21 & 2 & 23 & 52 & 73 & 30 & 0 \\
\hline $20-21$ & 21 & 0 & 21 & 31 & 52 & 30 & 0 \\
\hline $22-23$ & 12 & 0 & 12 & 40 & 52 & 40 & 0 \\
\hline $24-25$ & 5 & 0 & 5 & 47 & 52 & 37 & 7 \\
\hline $26-27$ & 2 & 0 & 2 & 50 & 52 & 50 & 0 \\
\hline $27-28$ & 21 & 2 & 23 & 52 & 73 & 30 & 0 \\
\hline
\end{tabular}




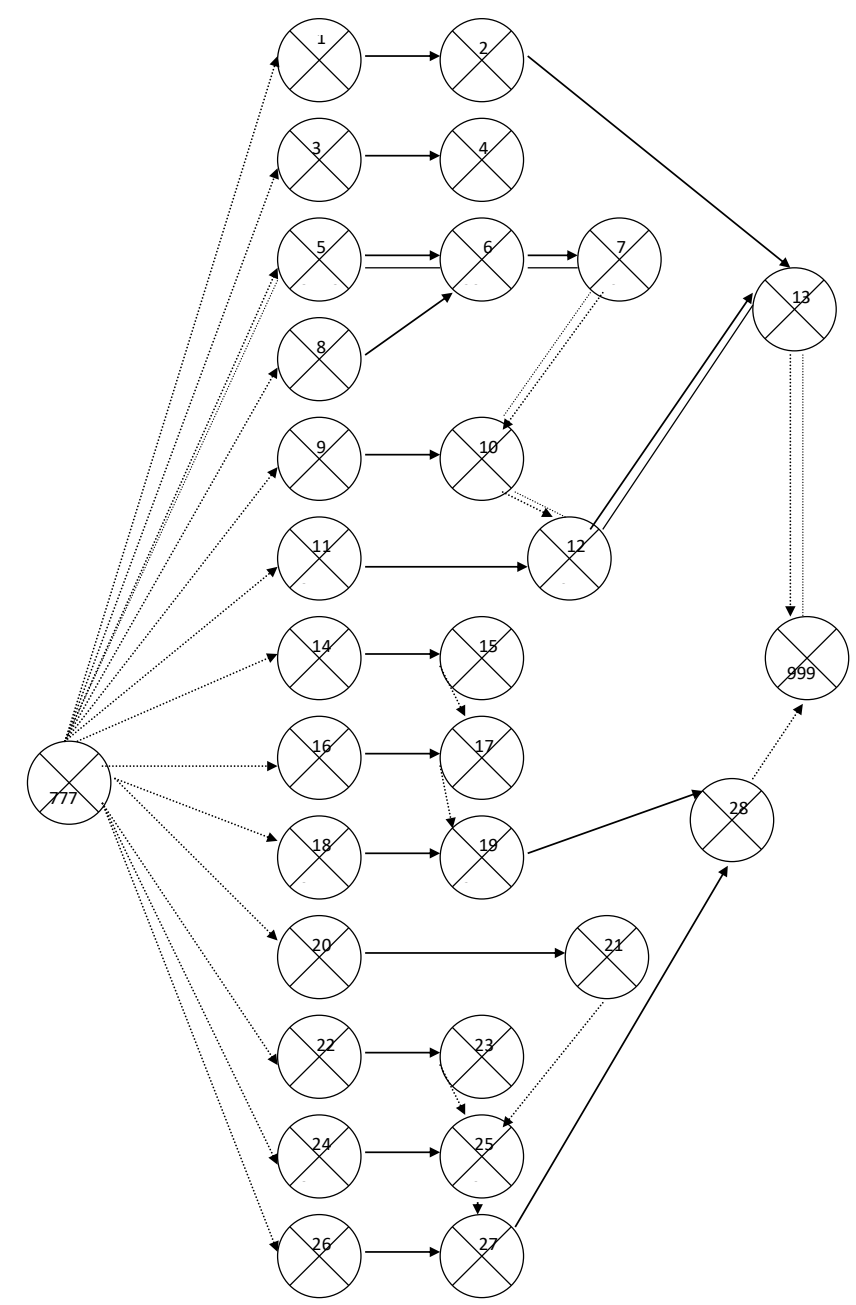

Рисунок 4. Комплекс маркетинговых работ и параметре сетевой модели

включить следующее условие: «Действия арендного договора прекращается досрочно в случае получения арендодателем представления комиссии по контролю качества бытового мультисервиса».

\section{Заключение}

Бытовые услуги относятся к социально значимым видам услуг, однако их потребление группой населения с наиболее высокими доходами в России растет быстрее, чем группой наименее обеспеченного населения. Поэтому среди приоритетных задач органов территориального управления является стимулирование развития тех форм предпринимательской деятельности, которые обеспечивают предоставление бытовых услуг, удовлетворяющих наименее обеспеченные слои населения по соотношению цена/ качество. Для этого необходимо как развитие конкуренции среди предпринимателей, так и создание условий для постоянного контроля качества, удовлетворения жалоб потребителей и их предотвращения.

Проблемы качества бытовых услуг, отмеченные экспертами, могут быть решены на основе объединения предпринимателей в саморегулируемые организации - ремесленные палаты по каждому профилю бытовых услуг, взаимодействующие с администрациями муниципальных округов. Представляется целесообразным организовать в субъекте федерации десять ремесленных палат по направлениям бытовых услуг, каждая из которых возглавляется координационным советом, разрабатывающим и выносящим на утверждение общим собранием членов СРО-ремесленной палаты стандарты профессиональной деятельности и стандарты оказания бытовой услуги.

В состав функций Координационного совета СРО - Ремесленной палаты целесообразно 
включить также решение проблем инфраструктурного обслуживания предпринимателей, а именно:

- формирование систематических взаимодействий с учреждениями начального, среднего и высшего профессионального образования;

- организация рекламной кампании, выставок, ярмарок;

- содействие в организации проектирования объектов БОН;

- логистической обеспечение деятельности предприятий БОН.

Члены СРО-ремесленной палаты обязаны разрабатывать и реализовывать политику качества, основные элементы которой разработаны автором на основании требований ГОСТ Р 50691-94. Модель обеспечения качества услуг», утвержденным Постановлением Госстандарта РФ от 29.06.1994 N 181.

В крупных городах качества жизни населения и цена жилья, в числе прочих факторов, зависит от уровня развития социально-бытовой инфраструктуры. Перспективной организационной формой предоставления бытовых услуг является бытовой мультисервис - это многопрофильный комплекс предприятий или индивидуальных предпринимателей, оказывающих бытовые услуги населения и располагающихся в пределах шаговой доступности друг от друга. Автор диссертационного исследования считает целесообразным размещение бытового мультисервиса на территории торгово-развлекательных комплексов, имеющих подземные паркинги (что необходимо для размещения автосервиса). Мультисервисное предприятие позволяет осуществлять предпринимательскую деятельность с меньшими издержками. Оформление бытового мультисервиса как ассоциации, основанной на добровольном членстве, с обязательствами его участников относительно соблюдения стандартов и регламентов качества, создает потенциальные условия для повышения бытовых услуг.

Размещение бытового мультисервиса на площадях торгово-развлекательных комплексов имеет следующие преимущества:

- население региона получает возможность одновременного доступа к широкому ассортименту услуг: бытовых, торговых, развлекательных туристских и пр.;

- увеличивается проходимость ателье, салонов и приемных пунктов предприятий бытового обслуживания, торговых точек за счет высокой посещаемости торгово-развлекательных комплексов;

- владельцы малых предприятий бытового обслуживания и индивидуальные предприниматели, оказывающие бытовые услуги и являющиеся членами бытового мультисервиса на территории торгово-развлекательного комплекса.

Авторами разработана сетевая модель координации межорганизационных взаимодействий при создании системы менеджмента качества бытовых услуг в мультисервисе, реализация которой позволила выделить критический путь и установить обязательные требования к арендному договору между собственником торговоразвлекательным комплексом, на территории которого предполагается создание бытового мультисервиса, и предпринимателями - арендаторами, оказывающими бытовые услуги населению.

\section{Библиографический список}

1. Baral Н. [и др.]. Economic evaluation of ecosystem goods and services under different landscape management scenarios // Land use policy. 2014. (39). C. 54-64.

2. Behara R.S., Gundersen D.E. Analysis of quality management practices in services // International Journal of Quality \& Reliability Management. 2001.

3. Chunawalla S.A. MARKETING PRINCIPLES AND PRACTICE. / S. A. Chunawalla, Himalaya Publishing House, 2018.

4. Dale B.G. [и др.]. Total quality management and theory: An exploratory study of contribution // Total quality management. 2001. № 4 (12). C. 439-449.

5. Dean JrJ.W., Bowen D.E. Management theory and total quality: improving research and practice through theory development // Academy of management review. 1994. № 3 (19). C. 392-418.

6. Gitlow H. S. Quality management systems: a practical guide / H. S. Gitlow, CRC press, 2000.

7. Hackman J.R., Wageman R. Total quality management: Empirical, conceptual, and practical issues // Administrative science quarterly. 1995. C. 309-342.

8. McDONALD M. Strategic marketing planning: theory and practice // The marketing book. 2016. C. 87.

9. Porral C.C., Stanton J. L. Principles of marketing / C. C. Porral, J. L. Stanton, ESIC Editorial, 2017. 
10. Slack N., Brandon-Jones A. Operations and process management: principles and practice for strategic impact / N. Slack, A. Brandon-Jones, Pearson UK, 2018.

11. Tarí J.J. Components of successful total quality management // The TQM magazine. 2005.

12. Vinzant J.C., Vinzant D. H. Strategic management and total quality management: challenges and choices // Public Administration Quarterly. 1996. C. 201-219.

13. Wilkinson A. Managing with total quality management: theory and practice / A. Wilkinson, Macmillan International Higher Education, 1998.

14. Yusof S.M., Aspinwall E. Total quality management implementation frameworks: comparison and review // Total quality management. 2000. № 3 (11). C. 281-294.

15. Басс А.Я., Разомасова Е.А. Механизм оценки развития сферы потребительских услуг в крупном городе // Вестник НГУЭУ. 2014. № 1.

16. Бурцева Т.А., Лысова Е.А. Особенности управления предприятиями сферы услуг // Вестник НГИЭИ. 2016. № 9 (64).

17. Герцик Ю.Г., Кайдалов С.А. Метрологический менеджмент и управление качеством как факторы, способствующие переходу предприятий медицинской промышленности на инновационную модель развития // Вестник Росздравнадзора. 2011. № 5. С. 42-45.

18. Демьянов Д.Г. Моделирование территориального развития сферы бытовых услуг // Вестник Пермского университета. Серия: Экономика. 2014. № 3.

19. ДЕНИСОВ М.В., ПИКАЛОВА М.А. МОДЕЛИ ПОДДЕРЖКИ НЕКОММЕРЧЕСКИХ ОРГАНИЗАЦИЙ, ОКАЗЫВАЮЩИХ СОЦИАЛЬНЫЕ УСЛУГИ НАСЕЛЕНИЮ 2015.С. 70-72.

20. Дробышев В.В. Формирование государственных минимальных стандартов и нормативов для регулирования качества социально значимых услуг // Вестник Тамбовского университета. Серия: Гуманитарные науки. 2007. № $12-2$.

21. Жиляева И.А. Опыт регулирования сферы услуг за рубежом [текст] /Родионов Д.Г., Жиляева И. А./ // В сборнике научных трудов XXII всеросийской научно-практической конференции «Экономика, экология, общество в ХХІ столетии».- СПб: СПбПУ.- 2017.- с. 132-137.

22. Жиляева И.А., Родионов Д.Г. Социально-экономические аспекты и тенденции предоставления услуг массового потребления в российской федерации // Экономика и предпринимательство. 2016. № 8 (73). С. 676-689.

23. Жиляева И.А., Родионов Д.Г. Прогнозы и планы развития потребительского рынка услуг массового потребления Санкт-Петербурга до 2020 г // Экономика и предпринимательство. 2016. С. 192-200.

24. Кликич Л. М. Эволюция сферы услуг: неравновесный подход // М.: Изд-во МСХА. 2004. С. 18.

25. Конева О.В. Малый бизнес: оценка вклада в развитие сферы услуг. монография - М., 2009.- 216 с.

26. Никитин А. В.Управление качеством на предприятии сферы услуг.- М., 2005.- 116 с.

27. Окрепилов В. В. Менеджмент качества: учебник // СПб.: Изд-во Политехн. ун-та. 2013.

28. Петрачкова Ю.Л. Развитие сферы услуг в системе потребительской кооперации // Вестник Белгородского университета кооперации, экономики и права. 2012. № 2. С. 264-267.

29. Плотникова Е. В. Оценка качества жилищного фонда как составляющая комплексной оценки условий формирования и развития человеческого капитала в регионах Российской Федерации [Текст]/ Е. В.Плотникова, О.В. Заборовская// Журнал правовых и экономических исслед.

30. Плотникова Е.В. Экономическая модель управления и развития жилищного фонда [Текст]/ Л.А.Гузикова, Е.В.Плотникова// В сборнике: Реструктуризация экономики и инженерное образование: проблемы и перспективы развития/ Сборник трудов научно-практической конф.

31. Рудакова О.Ю. Развитие институциональной модели управления качеством бытовых услуг (на материалах Ростовской области) // 2012.

32. Управление и организация в сфере услуг / К. Хаксевер и др.-СПб.: Питер, 2002.- 751 с. 